\title{
Plasma conductivity as a probe for ambient air admixture in an atmospheric pressure plasma jet
}

\author{
F. J. J. Peeters ${ }^{1}$, R. F. Rumphorst ${ }^{2}$, M. C. M. van de Sanden ${ }^{1,2}$
}

${ }^{1}$ DIFFER - Dutch Institute for Fundamental Energy Research, De Zaale 20, 5612 AJ Eindhoven, the Netherlands

${ }^{2}$ Eindhoven University of Technology, Department of Applied Physics, POB 513, NL-5600 MB Eindhoven, The Netherlands

(e-mail: f.j.j.peeters@differ.nl)

\begin{abstract}
By utilizing a fully floating double electrical probe system, the conductivity of a linear atmospheric pressure plasma jet (APPJ), utilizing nitrogen as process gas, was measured. The floating probe makes it possible to measure currents in the nanoamp range, in an environment where capacitive coupling of the probes to the powered electrodes is on the order of several kilovolts. Using a chemical kinetic model, the production of reactive nitrogen oxide and hydrogen-containing species through admixture of ambient humid air is determined and compared to the measured gas conductivity. The chemical kinetic model predicts an enhanced diffusion coefficient for admixture of $\mathrm{O}_{2}$ and $\mathrm{H}_{2} \mathrm{O}$ from ambient air of $2.7 \mathrm{~cm}^{2} \mathrm{~s}^{-1}$, compared to a literature value of $0.21 \mathrm{~cm}^{2} \mathrm{~s}^{-1}$, which is attributed to rapid mixing between the plasma jets and the surrounding air. The dominant charge carriers contributing to the conductivity, aside from electrons, are $\mathrm{NO}^{+}, \mathrm{NO}_{2}{ }^{-}$and $\mathrm{NO}_{3}^{-}$. Upon admixture of $\mathrm{O}_{2}$ and $\mathrm{H}_{2} \mathrm{O}$, the dominant neutral products formed in the $\mathrm{N}_{2}$ plasma jet are $\mathrm{O}$, NO and $\mathrm{N}_{2} \mathrm{O}$, while $\mathrm{O}_{2}\left({ }^{1} \Delta_{\mathrm{g}}\right)$ singlet oxygen is the only dominant excited species.
\end{abstract}

\section{Introduction}

Atmospheric Pressure Plasma Jets (APPJ's) have a large potential for cost efficient in-line surface modification, without the need for expensive and bulky vacuum equipment [1-4]. Moreover, jets can be used to treat complicated geometries, allowing for a wider range of applications than possible within the confines of a vacuum chamber. Other applications of 
APPJ include sterilization of medical equipment as well as plasmastimulated wound healing [5-7]. Independent of the specific application, quantitative knowledge of the charged, excited and radical species concentrations in the plasma jet is desirable. For surface modification, this entails knowing how much ambient air is admixed with the carrier gas as a function of distance to the treated surface in order to understand the effect of oxidizing agents on the surface or on the precursor molecules admixed in the jet. For both sterilization and wound healing applications, reactive and radical species such as $\mathrm{O}_{3}, \mathrm{NO}, \mathrm{NO}_{2}, \mathrm{OH}$ and $\mathrm{H}_{2} \mathrm{O}_{2}$, as well as excited singlet oxygen $\mathrm{O}_{2}\left({ }^{1} \Delta_{\mathrm{g}}\right)$, play a role in affecting microorganisms or mammalian tissues [8]. The ability to quantify these species formed during admixture of ambient air is, therefore, highly relevant. Measuring species concentrations of molecules and electrons in an APPJ can be very challenging due to the usually small dimensions of the jet $(<1 \mathrm{~mm})$ and is commonly achieved using laser diagnostics $[9,10]$ or using atmospheric pressure mass spectrometry [11]. The system studied in this work is a double linear APPJ system utilizing nitrogen as carrier gas, the VITO PlasmaLine ${ }^{\circledR}$ [12]. We take full advantage of the linear design of the plasma source by applying a double electrical probe to determine electron concentration and estimate positive and negative ion concentrations in the short-lived afterglow. The resulting conductivity data is analyzed using a chemical kinetic model, providing an effective diffusion coefficient for the admixture of ambient air into the jet and quantifying the dominant Reactive Oxygen Nitrogen Species (RONS), hydrogen containing species, as well as the dominant excited and charged species.

\section{Experimental setup}

\subsection{Plasma source}

The PlasmaLine ${ }^{\circledR}$ source utilizes a double slit atmospheric pressure dielectric barrier discharge with gaps of $0.5 \mathrm{~mm}$ with a $2 \mathrm{~mm}$ thick quartz and mica stack on the powered electrode and a stainless steel grounded electrode, see Figure 1. The total width of the system is $20 \mathrm{~cm}$, while the electrodes extend $2 \mathrm{~cm}$ into the source. A typical flow of $2001 / \mathrm{min}$ nitrogen gas is passed through the DBD's, resulting in two parallel $20 \mathrm{~cm}$ wide linear plasma jets, 
with an average gas flow velocity of around $7.3 \mathrm{~m} / \mathrm{s}$. The $\mathrm{N}_{2}$ process gas is 99.999\% pure, with contributions of $<3$ ppm $\mathrm{O}_{2}$ and $<2$ ppm $\mathrm{H}_{2} \mathrm{O}$ (Air Products Nitrogen Premier). A nearly sinusoidal voltage with a frequency of $55 \mathrm{kHz}$ and an amplitude of up to $10 \mathrm{kV}$ is applied to the electrodes using an AFS generator (G10S-V) and transformer (GT40), resulting in dissipated power densities of up to $80 \mathrm{~W} / \mathrm{cm}^{3}$ in the discharge, as determined from IV characteristics [13]. The discharge itself is sealed off from the atmosphere by virtue of the gas flow, while the plasma jets emerging from the DBD's are exposed to the surrounding air. A schematic of the plasma source is shown in Figure 1. The setup is placed inside a ventilation cabinet with an exhaust flow of $5 \mathrm{~m}^{3} \mathrm{~min}^{-1}$. The relative humidity RH of the ambient air in the lab is $\sim 50 \%$ at a temperature of $20^{\circ} \mathrm{C}$. The temperature of the plasma afterglow is monitored using a fiber optic thermometer attached to the central, grounded electrode, which is expected to thermalize with the output gas stream.

The plasma jets were studied spectroscopically in [14], where it was shown that the jets are in a late afterglow phase. This indicates that the plasma jets can be described as a flowing, recombining plasma, with the $\mathrm{N}_{2}$ DBD in the interior acting as a steady source of ions, electrons and, predominantly, atomic nitrogen. The average flow velocity through the DBD is $4 \mathrm{~m} / \mathrm{s}$, which results in a transit time of $\sim 5 \mathrm{~ms}$ for the gas to pass over the $2 \mathrm{~cm}$ deep electrodes. With the $55 \mathrm{kHz}$ driving voltage, this results in each $\mathrm{N}_{2}$ molecule being exposed to $\sim 280$ full discharge cycles before flowing out into the jet. Because of this, the plasma jets are considered to be a continuous plasma, despite the DBD source being a transient plasma.

\subsection{Flow sensor}

A custom-built hot-wire (HW) anemometer flow sensor is used to determine both the effective width of the plasma jet and the gas flow velocity between 0 and 14 $\mathrm{mm}$ from the source exit. The device is calibrated using a well-defined flow. The flow data is used to calculate the time-of-flight of particles as a function of distance to the source exit. Both the flow sensor and the calculation of time-offlight are treated in more detail in a previous publication [14].

\subsection{Electrical probe}


The custom-built double electrical probe used in this work is an electrically floating device with a built-in current readout display and voltage generator. The compact voltage generator uses a $9 \mathrm{~V}$ battery and a flyback DC-DC converter to apply bias voltages of up to $300 \mathrm{~V}$ to a probe head. The DC-DC converter operates on a period of $125 \mu \mathrm{s}$, which is much shorter than the RC time of the accompanying measurement circuit. This ensures that the bias voltage is effectively constant on the time-scale of the measurement. The measurement sensitivity is $0.1 \mathrm{nA}$. A completely floating system is made necessary by the strong capacitive coupling between probe heads and the high voltage electrodes of the plasma source, as well as the very low current to be measured. For the same reason, the entire device is electrically shielded and two identical probe heads are used, placed at exactly the same distance from the source, eliminating any influence of AC coupling on the measurements. With this method it is possible to measure DC currents in the $\mathrm{nA}$ range, in an environment where capacitive coupling to the powered electrodes is on the order of several kV's. The probe heads in contact with the jet are $2 \mathrm{~cm}$ long copper cylindrical wires with a diameter of $2 \mathrm{~mm}$, with only the sides facing each other not covered with insulating resin. The placement of the probes is depicted schematically in Figure 1. The insulation was applied to minimize DC currents drawn from anywhere but the opposite probe. The $2 \mathrm{~mm}$ cylindrical probes, combined with flow velocities on the order of $2 \mathrm{~m} / \mathrm{s}$, amount to a Reynolds number of $\mathrm{Re} \approx 200$, so that the jet flow profile is not significantly perturbed by the probes. Several sets of probes are used, each pair on a detachable base, with heart-to-heart probe separations of 5, 10, 15, 20 and $30 \mathrm{~mm}$. For a single double probe set, an IV characteristic is obtained by manually altering the bias voltage between the probes from $-300 \mathrm{~V}$ to $+300 \mathrm{~V}$ in steps and measuring the resulting current via a built-in high-impedance ammeter with an LCD display. The measurement bandwidth is limited to $\sim 4 \mathrm{~ms}$, ensuring that any fluctuations in the discharge (which has a period of $\sim 18 \mu \mathrm{s}$ ) are averaged out. Sufficient time is taken between each change of bias voltage to make certain the probe system and its shielding have attained their steady-state potentials. 


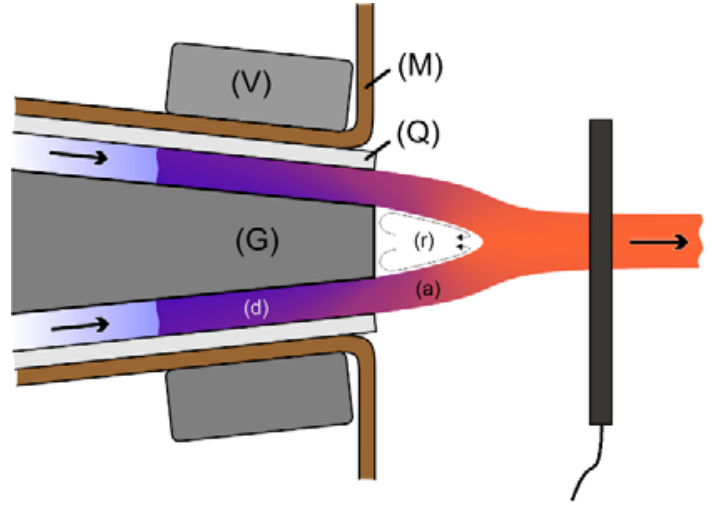

(P)

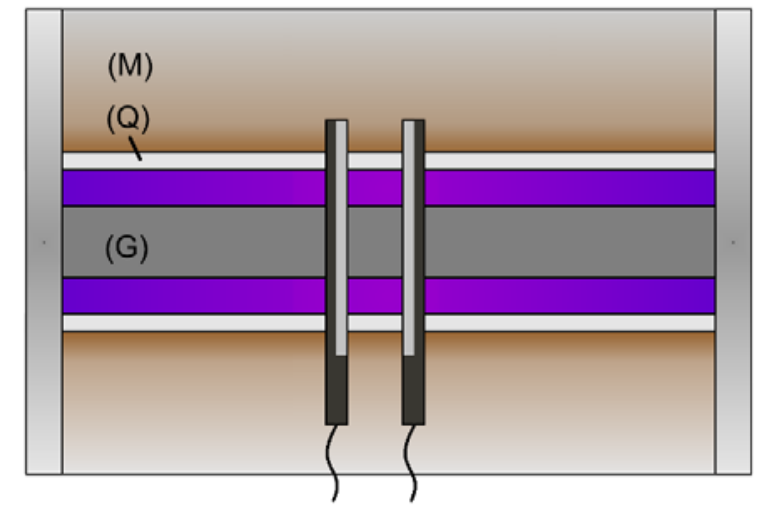

(P) (P)

Figure 1: Schematic cross section (left) and front view (right) of the PlasmaLine source. Indicated are high voltage electrodes $(\mathrm{V})$, mica dielectric barriers $(\mathrm{M})$, quartz dielectric barriers $(\mathrm{Q})$, grounded central electrode $(\mathrm{G})$, discharge region $(\mathrm{d})$, afterglow region (a), recirculation cell $(\mathrm{r})$ and the locations of the probes $(\mathrm{P})$.

\section{Results and discussion}

\subsection{Gas flow measurements}

Flow profiles from 0.4 to $14 \mathrm{~mm}$ from the source are measured, in steps of approximately $1 \mathrm{~mm}$, and combined to obtain the result depicted in Figure 2a. Since the flow sensor calibration is temperature dependent, these measurements were performed with plasma off, using only nitrogen at $T_{\text {cal }}=$ $20{ }^{\circ} \mathrm{C}$. With plasma on, the temperature of the gas increases by $\Delta T=50^{\circ} \mathrm{C}$, which leads to gas expansion and a proportionally higher flow velocities, which is taken into account by multiplying flow velocity by a factor of ( $T_{\text {cal }}$ $+\Delta T) / T_{\text {cal }}=343 \mathrm{~K} / 293 \mathrm{~K}$ in the analysis of the data. The flow profiles at various distances from the source were fitted with Gaussian functions to determine FWHM, which can be equated to the width of the contact area between the jet and electrical probes, as well as the characteristic length scale over which diffusion occurs. In the region where the two jets begin to overlap (from 5 to $10 \mathrm{~mm}$ from source, see Figure 2a), the flow in between the two jets is not fitted by Gaussian functions and is neglected in the analysis, as this is assumed to be part of a recirculation cell (see Figure 2b). The recirculation cell is the result of a low pressure region created in between the two jets, where the shear from the jets circulates the enclosed gas, see e.g. [15]. In the recirculation cell, as well as outside the FWHM of 
the flow profiles, the high residence time of plasma species is assumed to be large enough to lead to a negligible density. As discussed in the supplementary information of [14], the gas flow is best described by a k- $\varepsilon$ turbulent flow model. This model predicts a turbulence intensity (the ratio of velocity fluctuations to the velocity proper) of $\sim 20 \%$ within the jet. Due to the resulting enhanced mixing, the concentration of species over the width (i.e. FWHM) of the jets is assumed to be roughly uniform at each point along the flow direction. This assumption allows for the application of a 1D chemical kinetic model to the measured data, which will be discussed further in a later section. A time-of-flight of species from the source exit is determined from the average flow velocities within the FWHM regions of the measured flow, with an error of $10 \%$ due to uncertainty in the flow velocity. In Figure 2c, the FWHM is plotted as a function of this time-offlight, including an exponential fit of this data to obtain an interpolation of FWHM for each point along a plasma jet. 

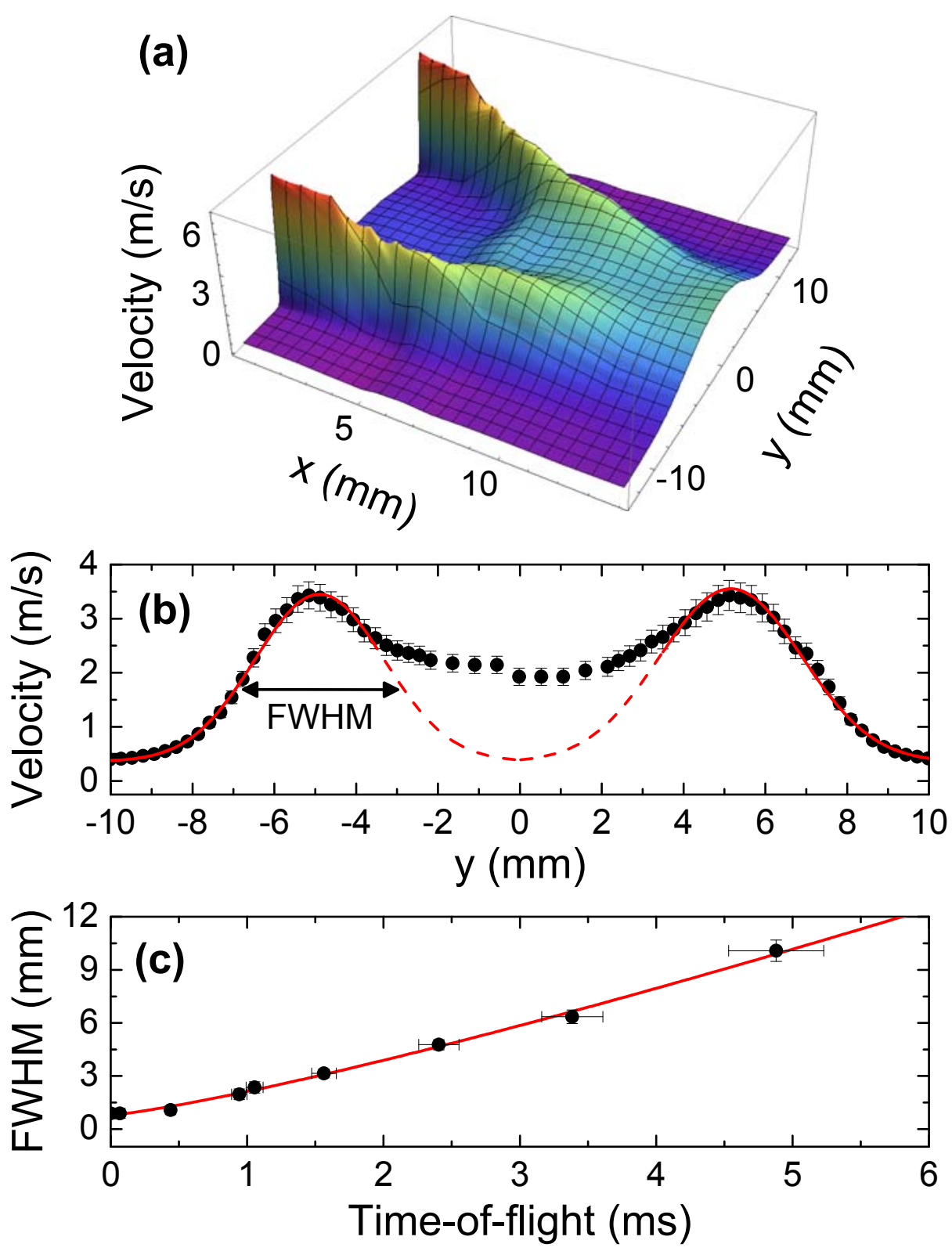

Figure 2: (a) Flow velocity as a function of position measured with the custom-built flow. The $\mathrm{x}$-axis is the distance to the source while the $y$-axis runs parallel to the source (i.e. the vertical direction in Figure 1). The figure is an interpolation of data obtained with a resolution of approximately 1 millimeter. (b) Example of the Gaussian fits of the crosssectional flow (red lines), excluding the recirculation zone in the center. (c) The FWHM of the Gaussian fits as a function of time-of-flight (points), including an exponential fit of these points (red line). 


\subsection{Double probe measurements}

Typical IV characteristics obtained using the floating double probe are depicted in Figure 3 for probe separations of 5, 10 and $15 \mathrm{~mm}$ at a distance of $1 \mathrm{~cm}$ from the source. The error bars in the graphs are based on the fluctuations observed in the current at each voltage, which are on the order of $2 \mathrm{nA}$, but increase with probe separation and distance to the source.

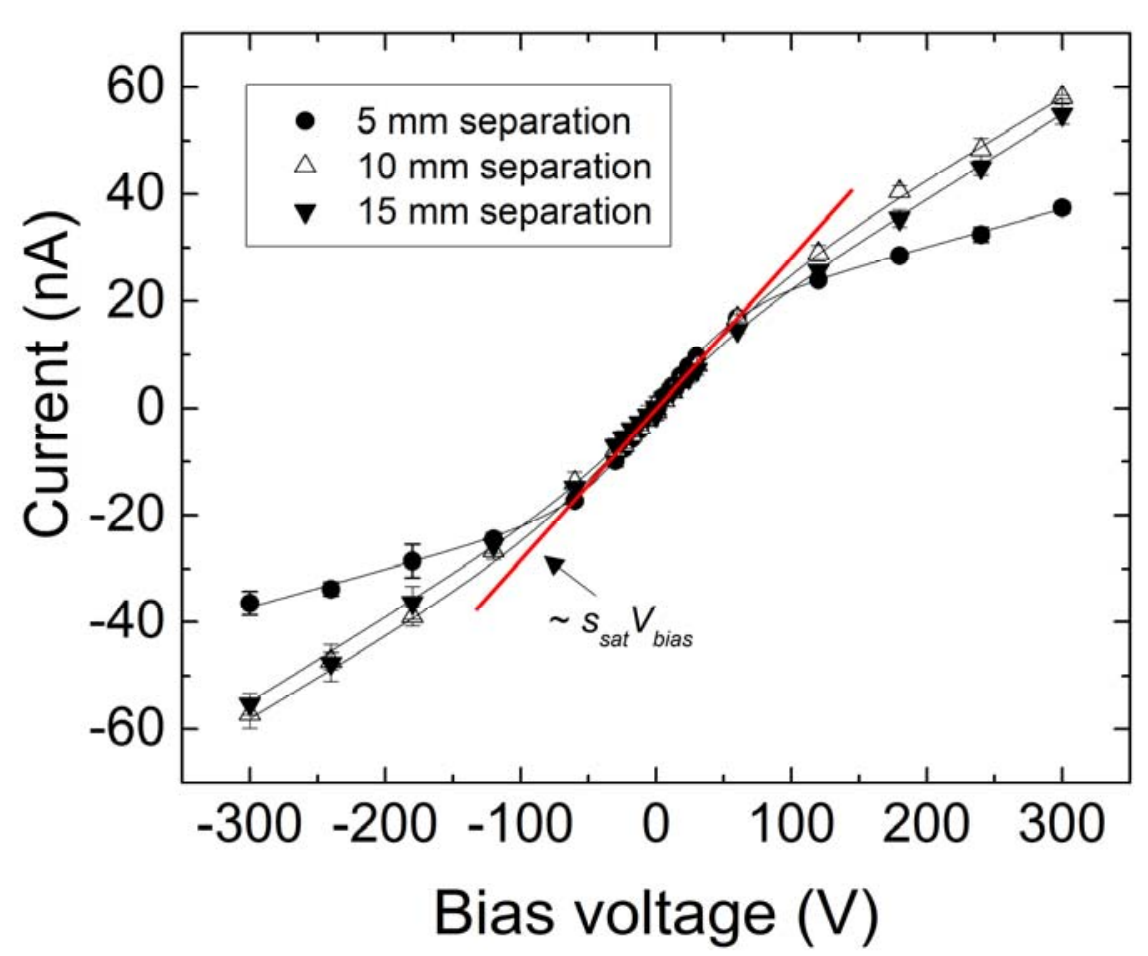

Figure 3: Typical IV characteristics for the floating double probe with probe separations of 5,10 and $15 \mathrm{~mm}$ at a distance of $1.0 \mathrm{~cm}$ from the source. The orientation of the probes is as depicted in Figure 1. The black lines are guides to the eye, while the red line is a fit of Equation (1) in the range of $-30 \mathrm{~V}$ to $+30 \mathrm{~V}$, assuming $k_{b} T_{e}<<e V_{\text {bias. }}$.

The IV characteristics depicted in Figure 3, have an S-shape typical of a double probe measurement, which at first glance appears to adhere to the standard relation for double probe current $i_{\text {probe }}$ as a function of $V_{\text {bias }}[16]$ :

$$
i_{\text {probe }}\left(V_{\text {bias }}\right)=i_{\text {sat }, 0} \frac{e^{e V_{\text {bias }} / k_{b} T_{e}}-1}{e^{e V_{\text {bias }} / k_{b} T_{e}}+1}+s_{\text {sat }} V_{\text {bias }},
$$


with $e$ the electron charge, $k_{b}$ the Boltzmann constant and $T_{e}$ the electron temperature, $i_{\text {sat }, 0}$ the probe saturation current at high $V_{\text {bias }}$ extrapolated to $V_{\text {bias }}=0$ and $s_{\text {sat }}$ the slope of the IV characteristic in the saturation regime at high $V_{\text {bias }}$. Equation (1) is commonly used for probe measurements in the low-pressure regime. However, when we apply Equation (1) to the data in Figure 3, $T_{e}=30,40$ and $50 \mathrm{eV}$ for probe separations of 5, 10 and $15 \mathrm{~mm}$, respectively, is found. These high electron temperatures are extremely unlikely in atmospheric pressure plasma, especially considering that a previous spectroscopic study of these plasma jets revealed a recombining plasma with no evidence for high temperature electrons in the spectra [14]. Moreover, $T_{e}$ should not depend on probe separation. Other authors find reasonable electron temperatures using similar electrical probe measurements on atmospheric pressure plasma jets and flames, though the process gas is either $\mathrm{He}$, Ar or a methane/oxygen mixture at high gas temperature [17-19], with Klagge and Tichý finding errors in $T_{e}$ no greater than $20 \%$ at atmospheric pressures [20]. Osaka et al. find a linear IV characteristic in methane/oxygen mixtures with $V_{\text {bias }}$ in the range $\pm 90 \mathrm{~V}$, similar to what is seen here [21]. We suggest that the actual double probe characteristic is lost within the noise around $V_{\text {bias }}=0$, as was also suggested by Wild et al. regarding the results of Osaka et al. [18]. This implies that $T_{e}$ is too low to be determined from the probe characteristic at our current measurement sensitivity. The saturation in probe current observed in Figure 3 for $\left|V_{\text {bias }}\right|>30 \mathrm{~V}$ is likely due to the draining of charged particles from the plasma between the probes, accounting for the weaker saturation seen with increasing probe separation. As will be determined later, charged particle densities at the probe locations are $<5 \cdot 10^{9} \mathrm{~cm}^{-3}$, which, with flow velocities on the order of $1 \mathrm{~m} / \mathrm{s}$ and jet cross-sectional areas of $\sim 50 \mathrm{~mm}^{2}$, provide a flux of charged particles of $<30 \mathrm{nA}$ to the area between the two probes. Once the probes begin to draw more current than is supplied by the gas flow, saturation sets in. This effect is not accounted for by Equation (1). The slope observed for $\left|V_{\text {bias }}\right|<30 \mathrm{~V}$ can, however, be identified as $s_{\text {sat }}$ in Equation (1), assuming $k_{b} T_{e}<<e V_{\text {bias }}$, and is related to the conductivity of the plasma between the probes. This allows us to treat the plasma between the probes as a series of resistors, from which ion and electron densities in the plasma jets 
can be derived. However, some effort must be taken to remove the influence of the plasma sheaths around the probes:

$$
\begin{aligned}
R_{\text {total }}=1 / s_{\text {sat }}=R_{\text {sheaths }}+R_{\text {plasma }}= \\
R_{\text {sheaths }}+\frac{1}{\sigma_{\text {plasma }}} \frac{\Delta d_{\text {probes }}-\Delta d_{\text {sheaths }}}{A_{\text {probes }}},
\end{aligned}
$$

where $R_{\text {total }}$ is the total impedance, consisting of the impedance of the plasma sheaths around the probes $R_{\text {sheaths }}$ and the impedance of the undisturbed plasma between the probes $R_{\text {plasma }}$. The latter depends on the plasma conductivity $\sigma_{\text {plasma }}$, the distance between the probes $\Delta d_{\text {probes, }}$, the total width of the plasma sheaths $\Delta d_{\text {sheaths }}$ and the contact area $A_{\text {probes }}$ between the probes and the plasma.

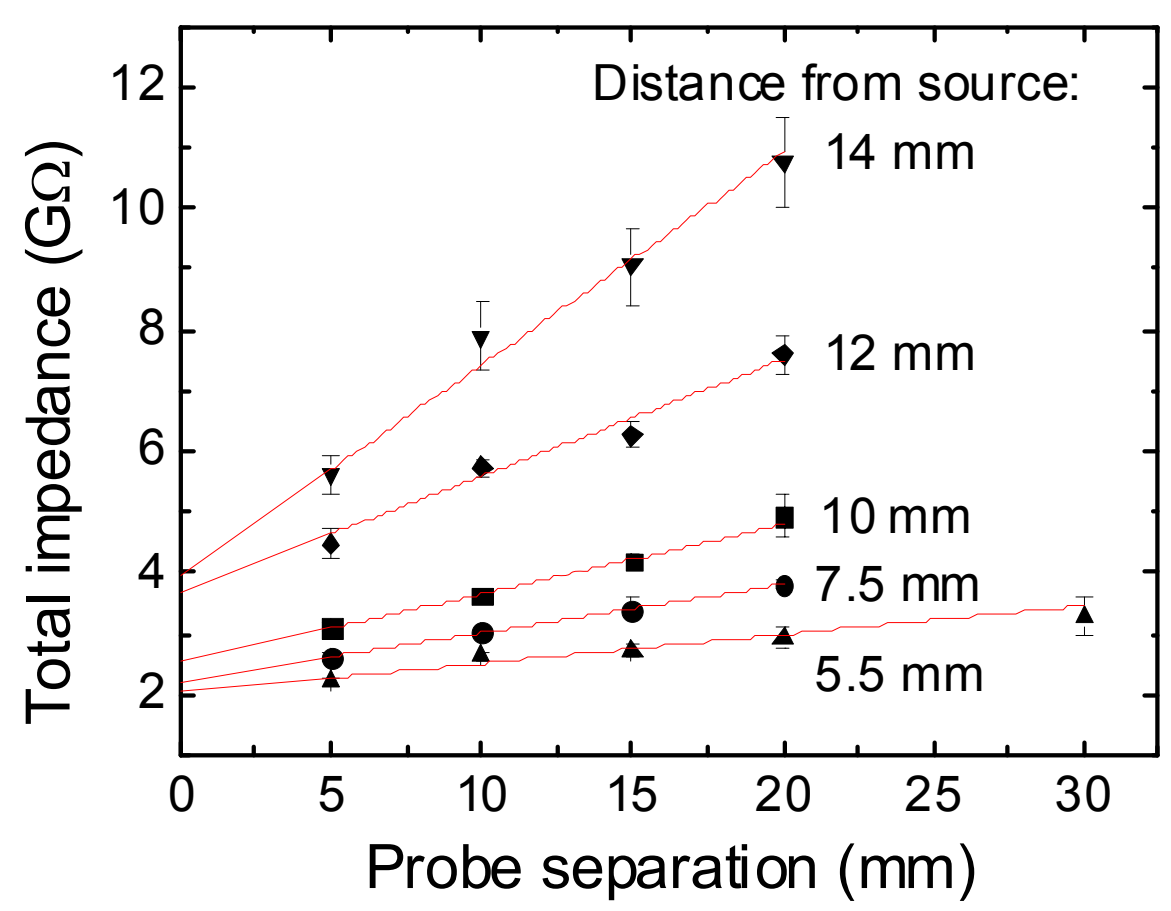

Figure 4: Impedance measured as a function of probe separation at different distances from the source, determined from voltages between -30 and $+30 \mathrm{~V}$. The slopes of the fitted lines are a measure of the charge density at different positions in the plasma jets. 
The impedance $R_{\text {total }}$, or $1 / s_{\text {sat }}$, is determined for different probe separations between $V_{\text {bias }}=-30 \mathrm{~V}$ to $+30 \mathrm{~V}$ for several distances from the source, see Figure 4. Measurements cannot be performed within $5.5 \mathrm{~mm}$ from the source, because discharging from the HV electrodes to the probe heads occurs within this distance. Within the measurement error, the data in Figure 4 shows a linear increase of impedance with probe separation, consistent with Equation (3). According to Equation (3), the slope is equivalent to $1 /$ $\sigma_{\text {plasma }} A_{\text {probes. }}$ The contact area $A_{\text {probes }}$ is given by twice (for both jets) the FWHM at the relevant position in the flow (see Figure 2c), multiplied by the probe diameter of $2 \mathrm{~mm}$. The conductivities $\sigma_{\text {plasma }}$ are plotted as a function of time-of-flight of species in the jets in Figure 5. To relate the conductivity values to electron and ion density the relation

$$
\sigma_{\text {plasma }}(t)=e\left(\mu_{e} n_{e}(t)+\sum_{i} \mu_{i} n_{i}(t)\right)
$$

is used, with $e$ the electron charge, $n_{e}$ the electron concentration, $\mu_{e}$ the electron mobility at the relevant electric field strength, and $\mu_{i}$ and $n_{i}$ the negative or positive ion mobilities or concentrations of species $i$, respectively. The maximum field strength for the undisturbed plasma can be estimated from the data at $14 \mathrm{~mm}$ from the source in Figure 4. Here, at $5 \mathrm{~mm}$ probe separation, the total impedance is $\sim 6 \mathrm{G} \Omega$, compared to $4 \mathrm{G} \Omega$ at the intercept, which should correspond to the highest observed ratio $R_{\text {plasma }} /$ $R_{\text {sheaths. }}$. The value of the impedance at the intercept can be used as a measure of the sheath impedances $R_{\text {sheaths }}$, assuming the sheaths are no wider than a few tenths of millimeters [22,23]. Since the current must be constant between the probes, a straightforward calculation using ohm's law shows that, at $V_{\text {bias }}=30 \mathrm{~V}$, a voltage drop of at most $10 \mathrm{~V}$ occurs over the undisturbed plasma between the sheaths, leading to a reduced electric field strength $E / n<80 \mathrm{mTd}$. Under these conditions, $\mu_{e}$ has a constant value of $10^{4} \mathrm{~cm}^{2} / \mathrm{Vs}$ at $350 \mathrm{~K}$ [24], which is consistent with the linear behavior of the resistivity with probe separation in Figure 4. Considering this low $E / n$, the probes will not significantly heat the electron gas between the probes. The mobilities $\mu_{i}$ of nitrogen, oxygen or nitrogen-oxygen ion species are on the order of $2 \mathrm{~cm}^{2} / \mathrm{Vs}$ and will therefore dominate the plasma conductivity only 
under conditions of high electron attachment [25-28]. In the following section, a chemical kinetic model is used to determine the contributions of electrons and ions to the conductivity.

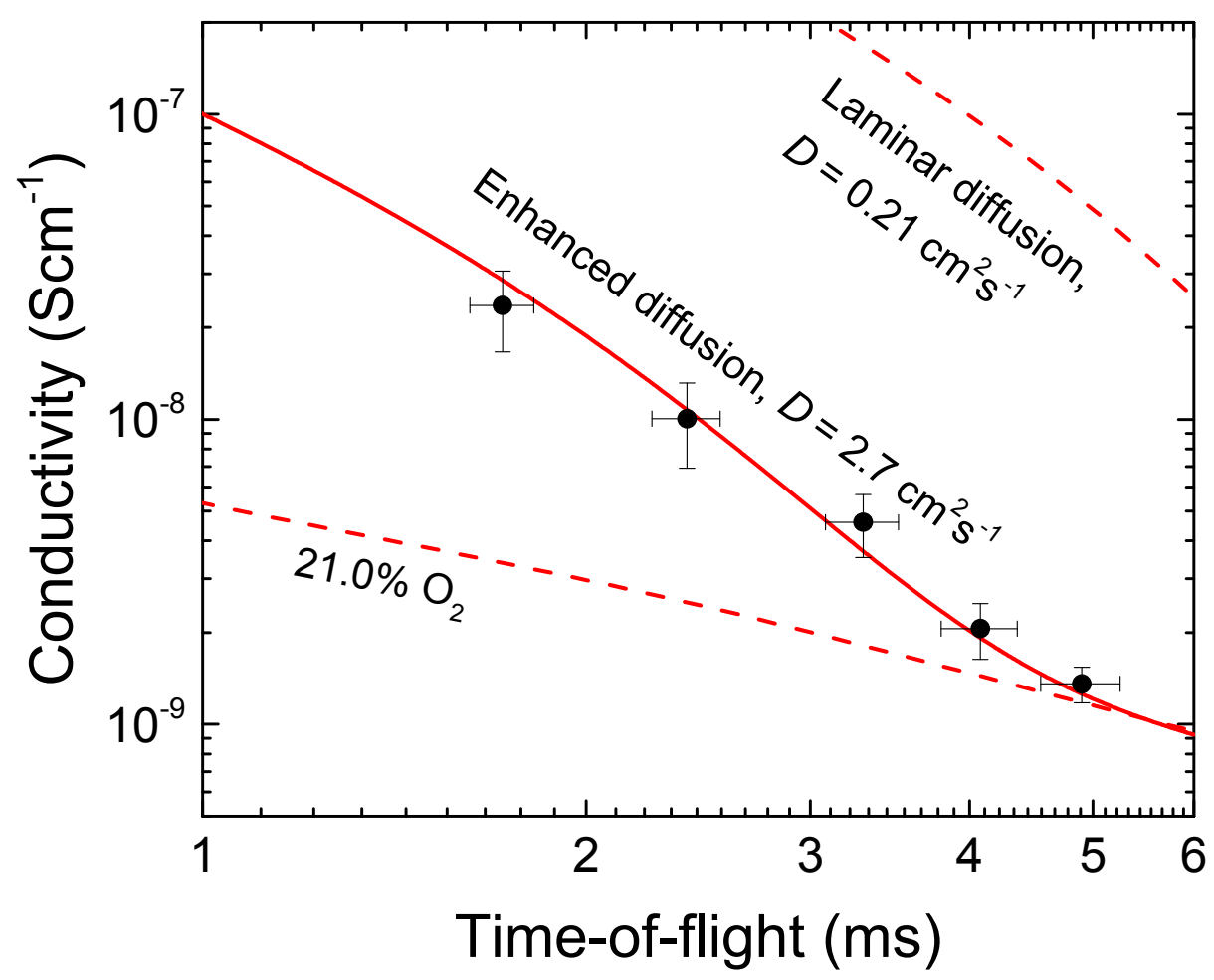

Figure 5: Double log plot of conductivity as a function of drift time in the plasma jet. Calculated conductivities for three different diffusion coefficients D are shown for comparison.

\subsection{Chemical kinetic model}

The 1D convection-reaction model was previously used in [14] and is applied here with some modifications. The main difference between [14] and the model presented here, is that previously it was used to describe the development of species along a single streamline, while here it describes the species concentrations averaged across the entire FWHM of the jet. The model contains 380 chemical reactions and 59 species, where for each species the governing continuity equation is given by: 


$$
\frac{\partial n_{x}(t)}{\partial t}=\sum_{i} k_{i} \prod_{j} n_{j, i}(t)+S_{x}(t)
$$

In this equation $t$ is time-of-flight, $n_{x}(t)$ the concentration of the species $x$ in units of $\mathrm{cm}^{-3}, k_{i}$ a reaction rate coefficient leading to either creation or destruction of species $x$ in units of $\mathrm{s}^{-1}, \mathrm{~cm}^{3} \mathrm{~s}^{-1}$ or $\mathrm{cm}^{6} \mathrm{~s}^{-1}$, depending on the order of the reaction, $n_{j, i}(t)$ the concentration of species $j$ involved in reaction $i$ and $S_{x}(t)$ a time-dependent source term for species $x$ in units of $\mathrm{cm}^{-3} \mathrm{~s}^{-1}$. The only source terms included are $S_{\mathrm{O}_{2}}(t)$ and $S_{\mathrm{H}_{2} \mathrm{O}}(t)$ for $\mathrm{O}_{2}$ and $\mathrm{H}_{2} \mathrm{O}$, respectively, with the forms:

$$
\begin{aligned}
& S_{\mathrm{O}_{2}}(t)=\frac{D}{l^{2}}\left(n_{\mathrm{O}_{2}}(t)-0.21 \cdot M\right), \\
& S_{\mathrm{H}_{2} \mathrm{O}}(t)=0.074 \cdot S_{\mathrm{O}_{2}}(t) .
\end{aligned}
$$

Equation (6) is based on Fickian diffusion of oxygen from the ambient air into the volume of the jet, with $D$ an effective diffusion coefficient in $\mathrm{cm}^{2} \mathrm{~s}^{-1}$, $M$ the total density of all species in the jet in $\mathrm{cm}^{-3}$, and $l$ a characteristic length scale over which this diffusion occurs, which is set equal to the FWHM of the jet as depicted in Figure 2c. The relative proportion $S_{\mathrm{H}_{2} \mathrm{O}} / S_{\mathrm{O}_{2}} \approx$ 0.074 in Equation (7) corresponds to the conditions of the ambient air in the lab, with $\mathrm{RH} \approx 50 \%$ at $20^{\circ} \mathrm{C}$. In this manner, mixing of ambient air with the plasma jet is modeled. The diffusion of $\mathrm{N}_{2}$ from the plasma jet to the ambient is neglected, since this exchange is implicitly covered by the diffusion of $\mathrm{O}_{2}$. Diffusion of species produced in the plasma jet to the ambient is also neglected, which is justified by the relatively high Péclet number $(l \cdot v / D>10)$ for advective transport in the direction of the flow (with velocity $v$ ) compared to diffusive transport perpendicular to the flow.

Equations (5)-(7) are solved for all 59 species, which are listed in Table 1. A constant gas temperature $T_{g}$ of $330 \mathrm{~K}$ is assumed throughout, which is the steady-state temperature of the central electrode during operation. Electrons are assumed to be cold, with $T_{e}=T_{g}$, so that electron impact reactions are 
neglected. Increasing $T_{e}$ has a minor effect on the model results, leading only to slightly slower attachment of electrons over time. The initial concentration of $\mathrm{N}_{2}(A)$ in the discharge is taken from literature values for $\mathrm{N}_{2}$ DBDs and is set to $10^{15} \mathrm{~cm}^{-3}$ [29-31]. The initial electron/ion concentration $n_{e}$ at the source exit is set at $10^{13} \mathrm{~cm}^{-3}$. This value does not affect the solutions to the model due to fast recombination during the first $100 \mu \mathrm{s}$ of drift time in the jet; i.e. any initial electron/ion concentration $>10^{11} \mathrm{~cm}^{-3}$ leads to the same result for time-of-flight in excess of $100 \mu \mathrm{s}$. The initial atomic nitrogen concentration, which drives most of the chemistry in the plasma jet, was measured in [14] and is set at $4.2 \cdot 10^{16} \mathrm{~cm}^{-3}$. The total species concentration $M$ is $2.2 \cdot 10^{19} \mathrm{~cm}^{-3}$, which remains constant to within $10 \mathrm{ppm}$ throughout the time frame of the calculation. As can be seen in the schematic of Figure 1, the high voltage electrodes of the DBD do not extend towards the source exit but are receded by at least $1 \mathrm{~mm}$. In terms of timeof-flight, the plasma has been decaying for an average of $300 \mu$ s before the starting point of the jet measurements. The initial conditions for the modeled species are therefore set at $t=-300 \mu \mathrm{s}$, as listed in Table 1, including the $\mathrm{O}_{2}$ and $\mathrm{H}_{2} \mathrm{O}$ impurities in the $\mathrm{N}_{2}$ carrier gas. 
Table 1: Species considered in the 1D chemical kinetic model. The top row shows all species for which a non-zero initial value is used at $\mathrm{t}=-300 \mu \mathrm{s}$ from the source exit.

\begin{tabular}{|c|c|c|c|c|c|c|c|}
\hline Species & $\mathbf{N}$ & $\mathrm{O}_{2}$ & $\mathbf{H}_{2} \mathbf{O}$ & $\mathbf{N}_{2}$ & $\begin{array}{l}\mathbf{N}_{2}(\mathbf{A} \\
\left.{ }^{3} \Sigma_{u}^{+}\right)\end{array}$ & & $\mathbf{N}_{4}^{+}$ \\
\hline $\begin{array}{l}\text { Initial } \\
\text { value } \\
\left(\mathrm{cm}^{-3}\right)\end{array}$ & $\begin{array}{l}4.2 \cdot 10^{1} \\
9\end{array}$ & $\begin{array}{l}7.5 \cdot 10^{1} \\
3\end{array}$ & $\begin{array}{l}5 \cdot 10^{1} \\
3\end{array}$ & $\begin{array}{l}2.2 \cdot 10^{1} \\
9\end{array}$ & $10^{15}$ & $10^{13}$ & $10^{13}$ \\
\hline $\begin{array}{l}\text { Species } \\
\text { (zero } \\
\text { initial } \\
\text { value) }\end{array}$ & \multicolumn{7}{|c|}{$\begin{array}{l}\text { Ground state: } \\
\mathrm{O}, \mathrm{O}_{3}, \mathrm{NO}, \mathrm{NO}_{2}, \mathrm{NO}_{3}, \mathrm{~N}_{2} \mathrm{O}, \mathrm{N}_{2} \mathrm{O}_{5}, \mathrm{OH}, \mathrm{HO}_{2}, \mathrm{H}, \mathrm{H}_{2}, \mathrm{H}_{2} \mathrm{O}_{2}, \\
\mathrm{HNO}, \mathrm{HNO}_{2}, \mathrm{HNO}_{3} \\
\text { Excited: } \\
\mathrm{N}\left({ }^{2} \mathrm{D}\right), \mathrm{N}\left({ }^{2} \mathrm{P}\right), \mathrm{O}\left({ }^{1} \mathrm{D}\right), \mathrm{O}\left({ }^{1} \mathrm{~S}\right), \mathrm{O}_{2}\left({ }^{1} \Delta_{\mathrm{g}}\right), \mathrm{O}_{2}\left({ }^{1} \Sigma_{\mathrm{g}}^{+}\right), \mathrm{N}_{2}\left(\mathrm{~B}^{3} \Pi_{\mathrm{g}}^{+}\right), \\
\mathrm{N}_{2}\left(\mathrm{C}^{3} \Sigma_{\mathrm{u}}^{+}\right), \mathrm{N}_{2}\left(\mathrm{a}^{1}{ }^{1} \Sigma_{\mathrm{u}}\right), \mathrm{NO}\left(\mathrm{A}^{2} \Sigma^{+}\right), \mathrm{NO}\left(\mathrm{B}^{2} \Pi\right)\end{array}$} \\
\hline
\end{tabular}

The only variable in the calculation is the diffusion coefficient $D$, which is varied to match the observed conductivity in Figure 5 via Equation (4). Figure 5 depicts three model results, one best fit and two extreme cases. The best fit is achieved for an effective diffusion coefficient $D=2.7 \mathrm{~cm}^{2} \mathrm{~s}^{-1}$, leading to a maximum $\mathrm{O}_{2}$ concentration of $4.4 \%$ in the plasma jet within 6 $\mathrm{ms}$ from the source. This effective diffusion coefficient is more than an order of magnitude higher than the diffusion coefficient of $\mathrm{O}_{2}$ in air of $0.21 \mathrm{~cm}^{2} \mathrm{~s}^{-1}$ [32], which is attributed to enhanced mixing of the gas flow from the source with ambient air. While the Reynolds number for the jets are low, at around $\mathrm{Re} \approx 500$, the jets emanating from the slits into open air create large eddy's in the shear layers between jet and air. This effect was studied by Suresh et al, who found low Reynolds number planar jets actually result in more vigorous mixing close to the nozzle exit than is the case for high Reynolds 
number jets [33]. This is confirmed when comparing with the 'laminar' diffusion coefficient of $0.21 \mathrm{~cm}^{2} \mathrm{~s}^{-1}$, which results in a maximum $\mathrm{O}_{2}$ concentration of only $0.4 \%$, with correspondingly lower concentrations of RONS and negative ions in the jet, leaving the electrons as the dominant charge carriers. This leads to a plasma conductivity $20 \mathrm{x}$ higher than observed, see Figure 5. To further demonstrate the use of the plasma conductivity as a measure of the admixture of ambient air, an extremely high effective diffusion coefficient was also used, leading to a maximum $\mathrm{O}_{2}$ concentration of $21 \%$. As seen in Figure 5, this leads to a conductivity much lower than observed.

The concentrations of selected species calculated for $D=2.7 \mathrm{~cm}^{2} \mathrm{~s}^{-1}$ are depicted in Figure 6. In regard to neutral species, it can be seen that within 1 $\mathrm{cm}$ of the source $\mathrm{N}$ and $\mathrm{O}$ are the dominant radical species while $\mathrm{NO}$ and $\mathrm{N}_{2} \mathrm{O}$ overtake $\mathrm{N}$ at $\sim 1 \mathrm{ppm}$ at greater distances from the source. Hydrogencontaining radicals have low concentrations at $\sim 50 \mathrm{ppb}$, with $\mathrm{OH}, \mathrm{HNO}_{2}$ and $\mathrm{HNO}_{3}$ radicals on the same order as $\mathrm{O}_{3}$. The dominant positive ion is $\mathrm{NO}^{+}$(of which some form cluster ions with $\mathrm{O}_{2}$ and $\mathrm{N}_{2}$ ), immediately from the source exit due to fast charge exchange between $\mathrm{N}_{4}{ }^{+}$and NO. Electrons attach quickly to the available $\mathrm{NO}_{2}$ and $\mathrm{NO}_{3}$, with the latter being virtually the only carrier of negative charge at more than $1 \mathrm{~cm}$ from the source, despite $\mathrm{NO}_{3}$ making up only $\sim 25 \mathrm{ppb}$ of the gas stream. Almost all excited species are quenched within $5 \mathrm{~mm}$ of the source, though a significant exchange of energy occurs towards singlet oxygen states $\mathrm{O}_{2}\left({ }^{1} \Delta_{\mathrm{g}}\right)$ and $\mathrm{O}_{2}\left({ }^{1} \Sigma_{\mathrm{g}}{ }^{+}\right)$, with a long lifetime $>1 \mathrm{~ms}$. The source of the ${ }^{1} \Sigma_{\mathrm{g}}{ }^{+}$singlet oxygen is via direct energy exchange between $\mathrm{N}_{2}\left(\mathrm{~A}^{3} \Sigma_{\mathrm{u}}{ }^{+}\right)$and $\mathrm{O}_{2}$, while ${ }^{1} \Delta_{\mathrm{g}}$ singlet oxygen results from recombination of two $\mathrm{O}$ atoms, which themselves are primarily formed from reactions between $\mathrm{N}_{2}\left(\mathrm{~A}^{3} \Sigma_{\mathrm{u}}{ }^{+}\right)$and $\mathrm{O}_{2}$, with a smaller contribution from reactions between atomic $\mathrm{N}$ and $\mathrm{O}_{2}$. 


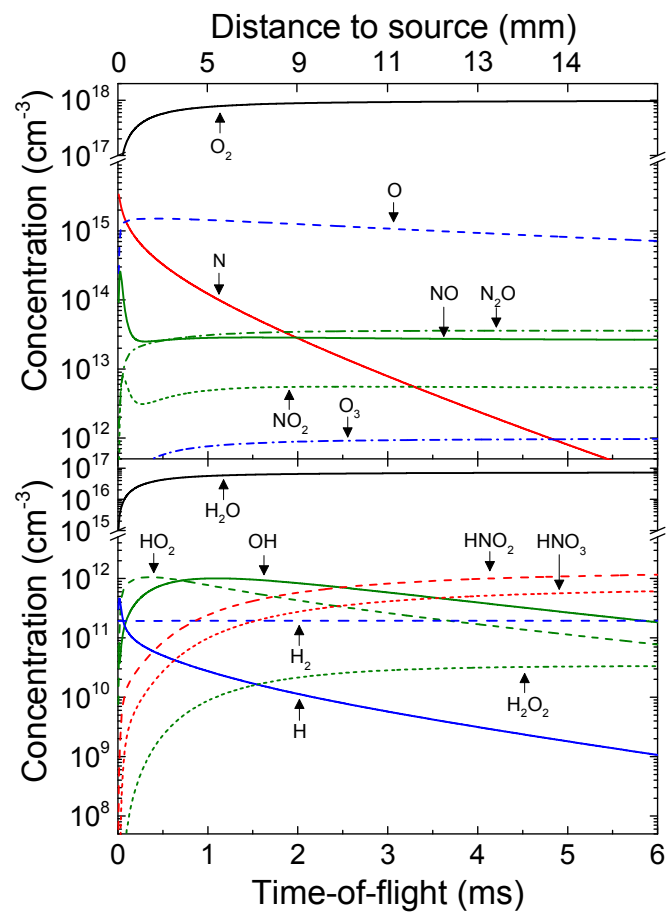

(a)

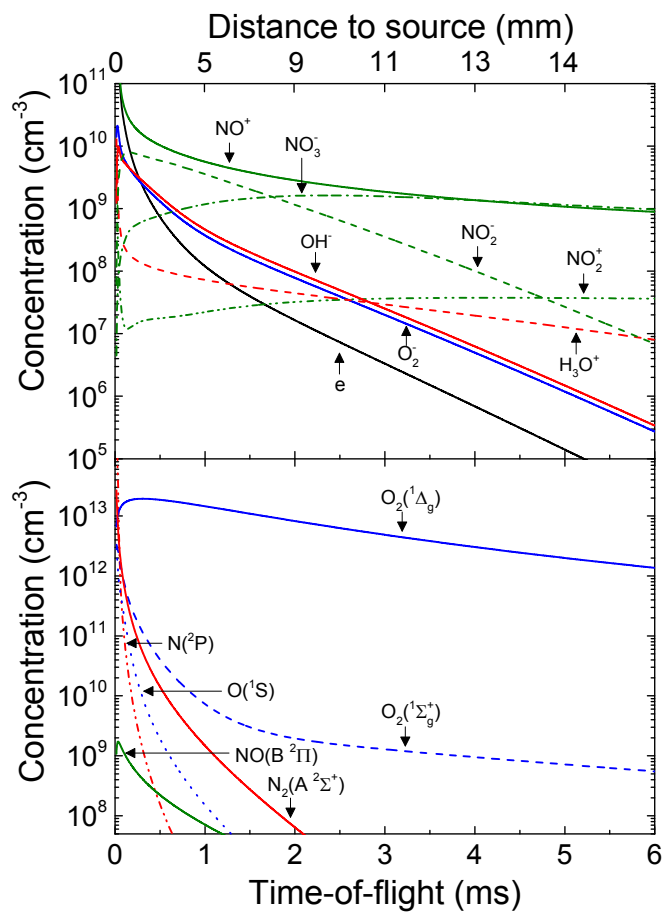

(b)

Figure 6: Calculated concentrations of dominant species from the chemical kinetic model as a function of time-of-flight (bottom axis) and distance from source (top axis) for (a) neutral species and (b) charged and excited species. The cluster ion concentrations $\mathrm{NO}^{+}\left(\mathrm{N}_{2}\right)$ and $\mathrm{NO}^{+}\left(\mathrm{O}_{2}\right)$ are included in $\mathrm{NO}^{+}$.

\section{Conclusions}

By utilizing a fully floating double electrical probe system, the low conductivity of a DBD plasma jet can be measured, despite the strong capacitive coupling between the high voltage electrodes of the DBD system and the probe heads. Very low DC currents on the order of tens of nanoamps can still be accurately determined in a multi-kilovolt $\mathrm{AC}$ environment. Instead of relying on sheath theory to interpret the double probe IV characteristic, it is possible to use variable probe separations to obtain the conductivity of the undisturbed plasma. In this way, charged species densities can be determined, while the electron temperature is too low to detect in the IV characteristic. By coupling the conductivity measurements to measured gas flow profiles and applying a 1D chemical kinetic model, the effective diffusion of ambient air into the plasma jet can be obtained. The effective diffusion coefficient is found to be $2.7 \mathrm{~cm}^{2} \mathrm{~s}^{-1}$, which is more than 
an order of magnitude higher than would be expected in a completely laminar flow regime and is likely the result of large scale eddy's forming in the shear layer between jet and open air near the nozzle exit. A similarly high mixing close to the nozzle exit can be expected in other plasma jet sources at relatively low Reynolds number operating in ambient air, including more common cylindrical sources. The kinetic model predicts a $4 \% \mathrm{O}_{2}$ concentration between $0.5-1.5 \mathrm{~cm}$ from the source exit and a $\sim 1$ ppm production of $\mathrm{NO}$ and $\mathrm{N}_{2} \mathrm{O}$. Even at $50 \%$ relative humidity, ambient air admixture leads to minimal $\mathrm{OH}, \mathrm{HNO}_{2}$ and $\mathrm{HNO}_{3}$ production in the $50 \mathrm{ppb}$ range. The ions $\mathrm{NO}^{+}, \mathrm{NO}_{2}{ }^{-}$and $\mathrm{NO}_{3}{ }^{-}$constitute almost all charged species within a few millimeters from the source exit. The single dominant excited species is ${ }^{1} \Delta_{\mathrm{g}}$ singlet $\mathrm{O}_{2}$, which is a desirable species for e.g. plasma medical applications.

\section{Acknowledgements}

This work was funded by the European Union's FP7 NMP project 'PlasmaNice'. The authors of this work thank R. Dams, R. Rego and E. van Hoof of the Flemish Institute for Technological Research (VITO) for their technical support. 


\section{Bibliography}

[1] Merche D, Vandencasteele N and Reniers F 2012 Atmospheric plasmas for thin film deposition: A critical review Thin Solid Films $\mathbf{5 2 0} 4219-36$

[2] Tendero C, Tixier C, Tristant P, Desmaison J and Leprince P 2006 Atmospheric pressure plasmas: A review Spectrochim. Acta - Part B At. Spectrosc. $612-30$

[3] Laroussi M and Akan T 2007 Arc-free atmospheric pressure cold plasma jets: A review Plasma Process. Polym. $4777-88$

[4] Schütze A, Jeong J Y, Babayan S E, Park J, Selwyn G S and Hicks R F 1998 The Atmospheric-Pressure Plasma Jet: A Review and Comparison to Other Plasma Sources IEEE Trans. Plasma Sci. 26 1685-94

[5] Kong M G, Kroesen G, Morfill G, Nosenko T, Shimizu T, van Dijk J and Zimmermann J L 2009 Plasma medicine: An introductory review New J. Phys. 11

[6] Laroussi M and Fridman A 2008 Plasma Medicine Plasma Process. Polym. 5 501-2

[7] Tipa R S and Kroesen G M W 2011 Plasma-Stimulated Wound Healing IEEE Trans. Plasma Sci. 39 2978-9

[8] Weltmann K-D and von Woedtke T 2017 Plasma medicine-current state of research and medical application Plasma Phys. Control.

Fusion 5914031

[9] Bruggeman P and Brandenburg R 2013 Atmospheric pressure discharge filaments and microplasmas: physics, chemistry and diagnostics J. Phys. D. Appl. Phys. 46464001

[10] Stancu G D, Janda M, Kaddouri F, Lacoste D A and Laux C O 2010 Time-Resolved CRDS Measurements of the N 2 ( A $3 \Sigma \mathrm{u}$ ) Density Produced by Nanosecond J. Phys. Chem. A 114 201-8

[11] Große-Kreul S, Hübner S, Schneider S, Ellerweg D, von Keudell A, Matejčík S and Benedikt J 2015 Mass spectrometry of atmospheric pressure plasmas Plasma Sources Sci. Technol. 2444008 
[12] VITO https://plasma.vito.be/en/equipment/plasmaline

[13] Peeters F J J and van de Sanden M C M 2015 The influence of partial surface discharging on the electrical characterization of DBDs Plasma Sources Sci. Technol. 2415016

[14] Peeters F J J, Yang R and van de Sanden M C M 2015 The relation between the production efficiency of nitrogen atoms and the electrical characteristics of a dielectric barrier discharge Plasma Sources Sci. Technol. 2445006

[15] Lin Y E and Sheu M J 1990 Experiments in Fluids Investigation of two plane parallel unventilated jets Exp. Fluids 10 17-22

[16] Cozens J R and Von Engel A 1965 Theory of the Double Probe at High Gas Pressure Int. J. Electron. 19 61-8

[17] Tichý M, Hubička Z, Š́cha M, Čada M, Olejníček J, Churpita O, Jastrabík L, Virostko P, Adámek P, Kudrna P, Leshkov S, Chichina M and Kment Š 2008 Langmuir probe diagnostics of a plasma jet system Plasma Sources Sci. Technol. 1814009

[18] Wild J, Kudrna P, Tichý M, Nevrlý V, Střižík M, Bitala P, Filipi B and Zelinger Z 2012 Electron Temperature Measurement in a Premixed Flat Flame Using the Double Probe Method Contrib. to Plasma Phys. 52 692-8

[19] Cada M, Hubicka Z, Sicha M, Churpita A, Jastrabik L, Soukup L and Tichý M 2003 Probe diagnostics of the RF barrier-torch discharge at atmospheric pressure Surf. Coatings Technol. 175 530-4

[20] Klagge S and Tichý M 1985 A contribution to the assessment of the influence of collisions on the measurements with Langmuir probes in the thick sheath working regime Czechoslov. J. Phys. 35 988-1006

[21] Osaka Y, Kobayashi N, Ohno N, Takamura S, Tanaka Y and Uesugi Y 2008 Measurement of plasma properties of the atmospheric oxycombustion flame by using double probe method Contrib. to Plasma Phys. 48 485-90

[22] Kiel R E 1969 Continuum electrostatic probe theory for large sheaths on spheres and cylinders J. Appl. Phys. 40 3668-73 
[23] Demidov V I, Ratynskaia S V. and Rypdal K 2002 Electric probes for plasmas: The link between theory and instrument Rev. Sci. Instrum. $\mathbf{7 3}$ 3409

[24] Wada T and Freeman G R 1981 Temperature, density, and electricfield effects on electron mobility in nitrogen vapor Phys. Rev. A 24 1066-76

[25] Stano M, Safonov E, Kučera M and Matejčík Š 2008 Ion mobility spectrometry study of negative corona discharge in oxygen/nitrogen mixtures Chem. List. 102 1414-7

[26] Young R A, Gatz C R, Sharpless R L and Ablow C M 1965 New method for measuring the rates of ionic transport and loss. I. Mobility of NO+ Phys. Rev. 138

[27] Snuggs R M, Volz D J, Schummers J H, Martin D W and McDaniel E W 1971 Mobilities and Longitudinal Diffusion Coefficients of MassIdentified Potassium lons and Positive and Negative Oxygen lons in Oxygen Phys. Rev. A 3 477-87

[28] Saporoschenko M 1965 Mobility of Mass-Analyzed N+, N, +, N, +, and N, + Ions in Nitrogen Gas Phys. Rev. 139 A352-6

[29] Panousis E, Merbahi N, Clément F, Yousfi M and Loiseau J-F 2009 Analysis of Dielectric Barrier Discharges under Unipolar and Bipolar Pulsed Excitation IEEE Trans. Dielectr. Electr. Insul. 16 734-41

[30] Stancu G D, Janda M, Kaddouri F, Lacoste D A and Laux C O 2010 Time-Resolved CRDS Measurements of the N 2 ( A $3 \Sigma \mathrm{u}$ ) Density Produced by Nanosecond J. Phys. Chem. A 114 201-8

[31] Šimek M 2003 Determination of N2(A) metastable density produced by nitrogen streamers at atmospheric pressure: 1 . Design of diagnostic method Plasma Sources Sci. Technol. 12 421-31

[32] Sakiyama Y, Graves D B, Chang H-W, Shimizu T and Morfill G E 2012 Plasma chemistry model of surface microdischarge in humid air and dynamics of reactive neutral species J. Phys. D. Appl. Phys. 45 425201

[33] Suresh P R, Srinivasan K, Sundararajan T and Das S K 2008 
Reynolds number dependence of plane jet development in the transitional regime Phys. Fluids $\mathbf{2 0}$ 